\title{
Local bearing empowerment towards smart society
}

\author{
Yuan Alfinsyah Sihombing $^{1 *}$, Nora Octavia Pasaribu ${ }^{1}$, Nur Hizrah Aini ${ }^{2}$, Al Trio Boy Beyto \\ Lumban $\mathrm{Gaol}^{3}$ \\ ${ }^{1}$ Faculty of Mathematics and Natural Science, Universitas Sumatra Utara \\ ${ }^{2}$ Faculty of Nursing, Universitas Sumatera Utara \\ ${ }^{3}$ Faculty of Culture, Universitas Sumatra Utara \\ *Email: yuanalfinsyah@yahoo.com
}

\begin{abstract}
Community Service Program (KKN) is a community service activity in certain areas as an implementation of the Tri Darma of Higher Education. Community service activities aim to provide field experience to students by assisting lecturers on the condition of the community directly and also to form an independent attitude and responsibility in carrying out community service activities. In addition, the service of KKN also aims to help the community in improving welfare. Community service activities are divided into three stages, namely preparation, implementation of activities on site, and evaluation. KKN educates students to continuously improve and maintain cooperation and a high level of social awareness to realize a work program that will be achieved. From this, students can increase their insight and experience that the success and success of a work program implementation is highly determined and influenced by good collaboration between fellow group members, supervisors and the local community. In this case we have proven that with good cooperation our work programs can be completed as expected.
\end{abstract}

Keyword: Knowledge, Education, Cooperation

\begin{abstract}
Abstrak
Pengabdian Kuliah Kerja Nyata (KKN) merupakan kegiatan pengabdian kepada masyarakat di daerah tertentu sebagai implementasi dari Tri Darma Perguruan tinggi. Kegiatan pengabdian KKN bertujuan untuk memberikan pengalaman lapangan kepada mahasiswa dengan pendampingan dosen tentang kondisi masyarakat secara langsung dan juga untuk membentuk sikap mandiri dan tanggung jawab dalam melaksanakan kegiatan pengabdian KKN. Selain itu, pengabdian KKN juga bertujuan untuk membantu masyarakat dalam meningkatkan kesejahteraan. Kegiatan pengabdian KKN dibagi menjadi tiga tahap, yaitu persiapan, pelaksanaan kegiatan di lokasi, dan evaluasi. KKN mendidik mahasiswa untuk senantiasa meningkatkan dan menjaga kerjasama dan tingkat kepedulian sosial yang tinggi untuk mewujudkan suatu program kerja yang akan dicapai. Dari hal tersebut maka mahasiswa dapat meningkatkan wawasan serta pengalaman bahwa keberhasilan dan kesuksesan suatu pelaksanaan program kerja sangat ditentukan dan dipengaruhi oleh kerjasama yang baik antara sesama anggota kelompok,dosen pembimbing maupun masyarakat setempat. Dalam hal ini kami telah membuktikan bahwa dengan adanya kerjasama yang baik maka program kerja kami dapat selesai sesuai yang diharapkan.
\end{abstract}

Kata Kunci: Pengetahuan, Mendidik, Kerjasama

\section{PENDAhUluAN}

Program Kuliah Kerja Nyata (KKN) merupakan salah satu program Universitas Sumatera Utara sebagai implementasi Tri Dharma Perguruan tinggi yaitu pengabdian mahasiswa terhadap masyarakat untuk membantu dan membimbing masyarakat dalam memanfaatkan sumber daya yang diharapkan serta mengembangkan potensi masyarakat. Program ini dilaksanakan dengan 
menyelaraskan kegiatan riset dan pengabdian kepada masyarakat dari dosen dan mahasiswa lintas keilmuan serta tetap membawa nilai-nilai kebersamaan USU.

Ketiga aspek Tri Dharma Perguruan Tinggi tersebut dilaksanakan dengan proposi yang seimbang, harmonis,dan terpadu dengan harapan agar kelak para lulusan USU dapat menjadi manusia yang berilmu pengetahuan dalam bidang masing-masing, mampu melakukan penelitian, dan bersedia mengabdi diri demi kemaslahatan umat manusia pada umumnya dan masyarakat Indonesia pada khususnya.

Sebagai kegiatan pendidikan dan pengajaran, KKN Reguler USU merupakan kegiatan integral dari kurikulum pendidikan Strata 1 (S1), hal ini berarti bahwa KKN USU merupakan program tidak berdiri sendiri dan tidak terpisahkan dari tujuan dan isi pendidikan lainnya. Perguruan Tinggi untuk melaksanakan misinya membantu mengatasi permasalahan penduduk, pembangunan, dan pembinaan lingkungan dengan karya dan bakti nyata. KKN yang dilaksanakan harus memenuhi empat prinsip, yaitu dapat dilaksanakan (feasibel), dapat diterima (acceptable) berkesinambungan (sustainable) dan partisipatif.

Secara garis besar tahap pelaksanaan KKN terbagi atas tiga tahap yakni tahap persiapan, tahap pelaksanaan, dan tahap evaluasi. Observasi dilakukan dengan metode: (1) tanya jawab, (2) dokumentasi, (3) melihat kelapangan secara langsung. Berdasarkan hasil observasi maka ditentukan program kerja KKN yang akan dilaksanakan meliputi program kerja kelompok.

\section{METODE PELAKSANAAN}

Kegiatan Kuliah Kerja Nyata di Kelurahan Pematang Marihat, Kecamatan Siantar Marimbun, Kota Pematang siantar dilakukan dengan menggunakan metode-metode sebagai berikut.

Metode pendekatan, yakni metode atau cara yang dilakukan mahasiswa untuk saling mengenal antara mahasiswa dengan warga dusun setempat. Pendekatan tidak hanya dilakukan dengan orang atau masyarakat, tetapi dengan situasi dan kondisi lingkungan sekitar pula.

\section{HASIL DAN PEMBAHASAN}

1. Kegiatan Mengajar di Sekolah dan PAUD

Mengajar di SD Negeri 122391 dilakukan sebanyak 3 hari yang mana TIM KKN memaksimalkan kesempatan tersebut untuk mengajar sesuai dengan bidang keahlian masingmasing diantaranya Matematika, Bahasa Indonesia, IPS, IPA, dan Mulok serta memberi motivasi kepada siswa mengenai pentingnya pendidikan.

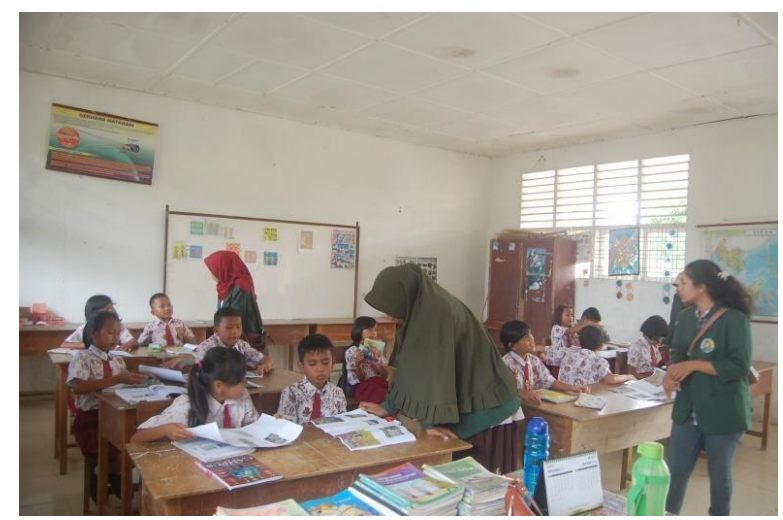

Gambar 3.1. Tim mengajar di ruang kelas SD Negeri 122391

2. Kelompok Belajar

Kelompok belajar ini dilakukan setiap hari Senin dan Rabu mulai pukul 15.00-17.00 WIB, namun siswa diperbolehkan untuk datang di hari Selasa, Kamis dan Jumat apabila ada tugas 
sekolah yang ingin didiskusikan. Kelompok belajar ini dikhususkan bagi siswa Sekolah Dasar untuk membantu mereka dalam membaca, berhitung maupun berkreasi.

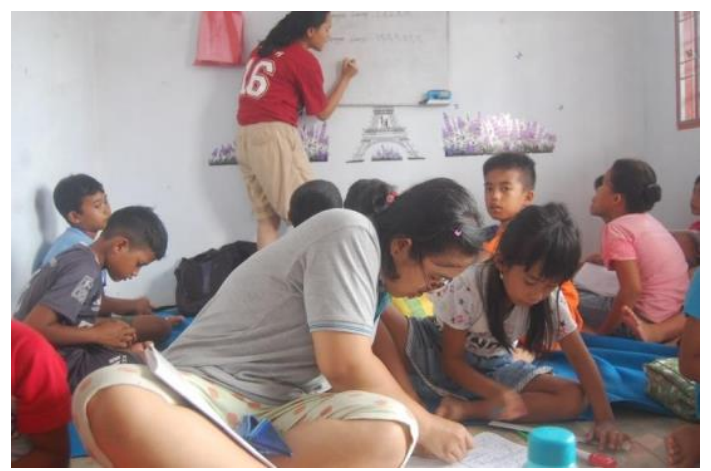

Gambar 3.2. Suasana pada kelompok belajar

3. Tanam Menanam Bibit Sayur

Tanam menanam bibit sayur dilakukan di SD Negeri 122391 dengan sasaran pelaksanaan siswa kelas 6. Kegiatan ini dimulai dengan pemberian materi menanam yang benar oleh TIM dan selanjutnya dipraktikkan langsung di lapangan sekolah. TIM memberikan bahan-bahan seperti tanah, polibag, dan bibit kepada siswa, selanjutnya siswa diarahkan untuk menanam.

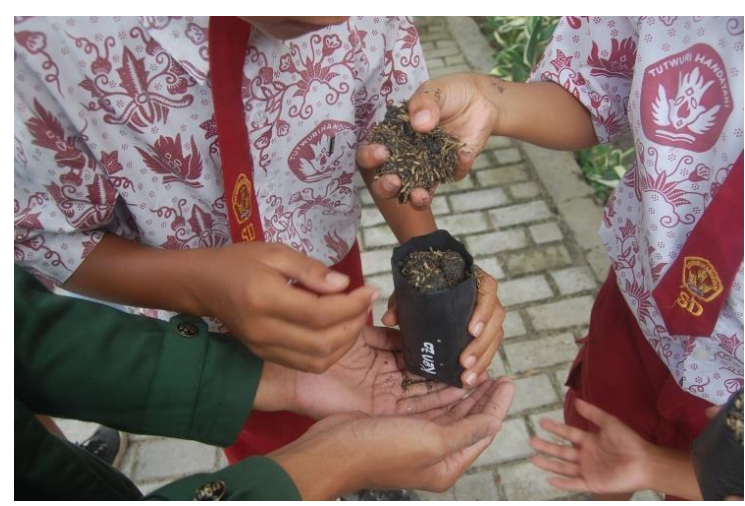

Gambar 3.3. Kegiatan tanam menanam sayur

4. Perayaan Hari Anak Nasional

Dalam perayaan Hari Anak Nasional, TIM mengadakan beberapa perlombaan seperti lomba mewarnai, menggambar, membaca puisi dan cerdas cermat matematika di SD Negeri 122391. Diambil 3 pemenang dari masing-masing perlombaan untuk diberikan hadiah dari TIM sebagai bentuk penghargaan kepada siswa.

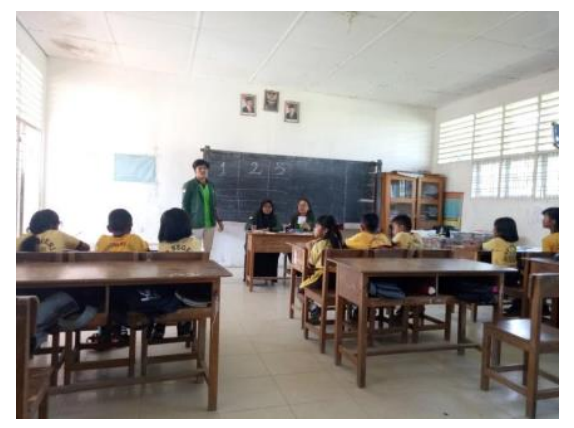

Gambar 3.4 Suasana lomba cerdas cermat matematika 


\section{KESIMPULAN}

KKN mendidik mahasiswa untuk senantiasa meningkatkan dan menjaga kerjasama dan tingkat kepedulian sosial yang tinggi untuk mewujudkan suatu program kerja yang akan dicapai. Dari hal tersebut maka mahasiswa dapat meningkatkan wawasan serta pengalaman bahwa keberhasilan dan kesuksesan suatu pelaksanaan program kerja sangat ditentukan dan dipengaruhi oleh kerjasama yang baik antara sesama anggota kelompok,dosen pembimbing maupun masyarakat setempat. Dalam hal ini kami telah membuktikan bahwa dengan adanya kerjasama yang baik maka program kerja kami dapat selesai sesuai yang diharapkan.

\section{UCAPAN TERIMAKASIH}

Ucapan Terima Kasih kepada Lembaga Pengabdian kepada Masyarakat Universitas Sumatera Utara yang telah Menfasilitasi Pelaksanaan Pengabdian Masyarakat IbM Mono Tahun (Dosen Muda).

\section{DAFTAR PUSTAKA}

LPPM USU. 2019. Buku Panduan Kuliah Kerja Nyata Pembelajaran Pemberdayaan Masyarakat (KKN-PPM) Universitas Sumatera Utara Tahun 2019. Medan: LPPM USU.

Nasution, Sri Wahyu Hutami. 2017. Implementasi Kebijakan Peralihan Pajak Bumi Dan Bangunan Perdesaan dan Perkotaan PBB-P2 Menjadi Pajak Daerah (Studi Pada Badan Pengelola Keuangan Daerah Kota Pematangsiantar). Skripsi. Medan: Departemen Ilmu Administrasi Publik, FISIPOL USU.

Roidah, Ida Syamsu. 2014. Pemanfaatan Lahan dengan Menggunakan Sistem Hidroponik. Jurnal Universitas Tulungagung BONOROWO. Vol: 1, No: 2, pp. 43-50.

Rubiatik, S., Sartini, dan R. Lubis. 2015. Skrining Fitokimia dan Uji Antimikroba Ekstrak Kasar Bawang Batak (Allium Cinense) terhadap Bakteri Staphylococcus aureus Dan Escherichia coli. BioLink Jurnal Biologi Lingkungan, Industri dan Kesehatan. Vol: 2, No:1, pp. 1-10. 